Note on Mr. Gifford's method of measuring refractive indices

This content has been downloaded from IOPscience. Please scroll down to see the full text. 1913 Trans. Opt. Soc. 1457

(http://iopscience.iop.org/1475-4878/14/1/305)

View the table of contents for this issue, or go to the journal homepage for more

Download details:

IP Address: 134.121.47.100

This content was downloaded on 02/10/2015 at 12:01

Please note that terms and conditions apply. 


\title{
NOTE ON MR. GIFFORD'S METHOD OF MEASURING REFRACTIVE INDICES.
}

\author{
By S. D. Chalmers, M.A. \\ Read 8th January, 1914.
}

IN the measurement of standard refractive indices, Mr. Gifford has aroided the troublesome measurement of the angle of the prism by using a $60^{\circ}$ prism polished on the three faces, and taking the mean value of the deviations produced at each angle as being the deviation produced by a prism of exactly $60^{\circ}$.

The purpose of this note is to point out that each of the three angles of such a prism can be readily obtained by the auto-collimating method described by the author and Mr. Ryland to the Optical Society.

In this method the auto-collimating telescope is used to direct a beam of nearly parallel light normally to one face, A B, of the prism. Part of the light is reflected. The transmitted beam is divided into two: one part, after being totally reflected at the face, $\mathrm{BC}$, falls nearly normally on the other face, $\mathrm{CA}$, and is reflected back nearly along its own path to form an image in the auto-collimating telescope, nearly coincident with the image obtained by reflection at the front face. The observed difference in direction of these two beams is $2 n$ times difference between the angles $\mathrm{A} C \mathrm{~B}$ and $\mathrm{CB} \mathrm{A}$; by observing the other beam we get $2 n$ times the difference between the angles A C B and C A B, and hence the three angles of the prism. ( $n$ is the refractive index.)

As the differences to be measured are small 
we can obtain the angles of the prism with a very high degree of accuracy.

Incidentally the goodness of the surfaces is subjected to a severe test, since the angle of incidence for the total reflection is about $60^{\circ}$ and any sphericity shows itself in marked astigmatism in the image. By displacing the prism we can easily verify that the whole of each reflecting face is plane.

The knowledge of the angles of the prism, though not essential to Mr. Gifford's method, is very useful, in that the accuracy of each individual reading, as compared with the mean of three, is at once given.

In reply to a question put by a member as to whether, with the method in question, any errors in the refractive indices would not become more apparent and more disturbing than by the usual methods,

Mr. T. Smith said he thought it must be taken for granted that in the specimens measured by Mr. Gifford the refractive index did not vary appreciably; otherwise his results would have very little meaning. He believed $\mathrm{Mr}$. Gifford had measured his refractive indices to something like six or seren places. At any rate, all the interest of the method chiefly lay in that the measurements, on the assumption that the material was homogeneous, could be taken to quite a high order of accuracy. 